\title{
Repertorio bibliográfico anotado de monografías de lucha leonesa (1977-2015)
}

\author{
José A. ROBLES-TASCÓN1* \& Héctor GARCÍA-ROBLES ${ }^{2}$ \\ Universidad de LEÓN (España) \\ Ayuntamiento Villaquilambre, León (España) \\ Recepción: 20/10/2017; Aceptación: 06/11/2017; Publicación: 09/11/2017.
}

\section{Resumen}

ORIGINAL PAPER

El presente estudio tuvo por objeto crear un repertorio bibliográfico anotado sobre lucha leonesa. Para su elaboración se partió de la biblioteca del primer autor y se consultaron los catálogos de Biblioteca Nacional de España, Bibliotecas Públicas del Estado, Red de Bibliotecas Universitarias Españolas, así como la Base de datos de libros editados en España de la Agencia Española del ISBN, mediante las palabras clave "lucha leonesa" y "aluche". Componen el repertorio un total de 19 monografías, publicadas entre los años 1977 y 2015. En ellas se aprecia la dimensión eminentemente local de este deporte tradicional, el apoyo que ha recibido por diversas instituciones públicas y privadas, así como su doble dimensión como deporte y como tradición sólidamente enraizada en la cultura leonesa.

Palabras clave: Lucha leonesa; aluche; deportes de combate; luchas tradicionales; León; España.

\section{Repertório bibliográfico anotado de monografias de luta leonesa (1977-2015)}

\section{Resumo}

O presente estudo teve por objetivo elaborar um repertório bibliográfico anotado sobre a luta leonesa. Para a sua elaboração, partiu-se da biblioteca do primeiro autor e consultaram-se os catálogos da Biblioteca Nacional de Espanha, Bibliotecas Públicas do Estado, Rede de Bibliotecas Universitárias Espanholas, assim como a Base de dados de livros editados em Espanha da Agência Espanhola do ISBN, mediante as palavras chave "luta leonesa" e "alcuche". 0 repertório é constituído por um total de 19 monografias, publicadas entre os anos 1977 e 2015. Nelas se aprecia a dimensão eminentemente local deste desporto tradicional, e o apoio recebido por diversas instituições públicas e privadas, assim como a sua dupla dimensão, como desporto e como tradição solidamente enraizada na cultura leonesa.

Palavras-chave: Luta leonesa; aluche; desportos de combate; lutas tradicionais; León; Espanha.

\section{Annotated bibliography about Leonese wrestling (1977-2015)}

\section{Abstract}

The purpose of this study was to create an annotated bibliography about Leonese wrestling. The first author's library was the starting point and then the catalogs of the National Library of Spain, Public Libraries of Spain, Spanish University Libraries Network, as well as the Spanish ISBN Agency Database of books published in Spain were consulted by using the keywords "lucha leonesa" and "aluche". The annotated bibliography comprises a total of 19 monographs, published between 1977 and 2015. As a whole, they show the eminently local dimension of this traditional sport, the support it has received from several public and private institutions, as well as its double dimension as a sport and as a tradition solidly rooted in Leonese culture.

Keywords: Leonese wrestling; aluche; combat sports; traditional wrestling styles; León; Spain.

\section{Introducción}

La lucha leonesa o aluche es la única modalidad de lucha tradicional que, de todas las que existían antaño, sobrevive actualmente en una parte de la provincia de León (España). Hoy día es un deporte de combate en el que dos contendientes, con agarre fijo a sendos cinturones de cuero, tratan de tirar a su contrario al suelo mediante una serie de mañas o técnicas. De supuesto origen astur y prerromano, los aluches conservan un cierto sabor rural y primitivo con que nacieran, de ahí sus raíces centenarias. En la actualidad los aluches o competiciones de lucha leonesa son espectáculos deportivos que siguen gozando de gran popularidad a nivel local, y pueden considerarse una verdadera seña de identidad de la cultura leonesa (Robles Tascón \& Álvarez del Palacio, 2001). Por este motivo, mediante el Acuerdo 33/2017, de 29 de junio, la Junta de Castilla y

*E-mail: jarobt@unileon.es 
León declaró recientemente a la lucha leonesa Bien de Interés Cultural de carácter inmaterial, considerando que

El aluche o Lucha Leonesa es un deporte autóctono tradicional, legado de una costumbre y tradición transmitida de forma oral de generación en generación mantenida a través de los siglos hasta nuestros días, que se ha ido adaptando a las formas y convenciones del deporte moderno sin perder su propia esencia, convirtiéndose en una práctica federada con competiciones regulares, que forma parte de la herencia histórico-cultural de la Comunidad de Castilla y León.

Como tantas otras actividades lúdicas tradicionales de carácter popular, la mayor parte de la cultura y del conocimiento propio de la lucha leonesa se ha transmitido - cuando se ha hecho de forma oral, visual y, valga el término, corporal. Solo recientemente, y salvando las referencias a la lucha leonesa que de forma puntual se han ido acumulando a lo largo de la historia (véanse e.g., Robles Tascón, 2002, 2003), comenzaron a publicarse monografías específicas sobre este deporte. En este sentido, Fernández (2002, p. 9) señalaba hace algunos años que "Si había una verdad irrefutable en la lucha leonesa, hasta ahora, es que se trataba de un deporte mal tratado por la literatura, que apenas era citada en unos pocos textos y muy de pasada", opinión que también mantenían otros autores (López Rodríguez \& Flórez de Celis, 1995; Robles Tascón, 2002). Esto contrasta, por ejemplo, con la amplia literatura existente sobre deportes de combate más aristocráticos como la esgrima (véanse e.g. las tempranas bibliografías de d'Orvenipe, 1898, 1901; Leguina, 1891), o sobre las artes marciales asiáticas, en general (Pérez-Gutiérrez, Brown, Álvarez, \& Gutiérrez-García, 2014) y específicamente en España (Pérez-Gutiérrez \& Gutiérrez-García, 2008; Pérez-Gutiérrez, Gutiérrez-García, \& Álvarez del Palacio, 2013).

Con todo, existe ya en la actualidad un cierto número de monografías específicas sobre lucha leonesa cuya existencia merece ser divulgada. El presente estudio tiene por objeto dar a conocer estas monografías mediante la elaboración de un repertorio bibliográfico anotado que pueda servir de ayuda y referencia a los estudiosos de la lucha leonesa.

\section{Método}

\subsection{Definición del objeto de estudio}

El repertorio recoge las monografías sobre lucha leonesa publicadas hasta el año 2015. Entendiendo como tales aquellas en las que la lucha leonesa es el principal contenido de la monografía, y no una parte de la misma como podrían ser entradas de diccionarios, enciclopedias, estudios sobre juegos y deportes tradicionales, actas de congresos, etc. La definición de monografía, como "documento que no se publica en serie" (AENOR, 1994) también excluye las revistas y documentos similares (periódicos, anuarios, boletines, etc.), aunque estos sean de lucha leonesa. Siguiendo el criterio de Pérez-Gutiérrez (2012), tampoco se han tenido en cuenta reglamentos de competición, ni trabajos académicos en forma de tesis doctoral, tesina, trabajo fin de máster, trabajo fin de grado, etc., a menos que estos trabajos hayan sido posteriormente publicados por alguna editorial, como fue el caso por ejemplo de la temprana obra de García Blanco (1977).

\subsection{Fuentes de información}

El presente estudio parte de la propia biblioteca del primer autor, estudioso de la lucha leonesa desde la década de 1990. Aunque se tenía bastante certeza de que esta biblioteca contenía la totalidad de monografías publicadas sobre los aluches, también se consultaron los catálogos de la Biblioteca Nacional de España (BNE), Bibliotecas Públicas del Estado (CCBIP), Red de Bibliotecas Universitarias Españolas (REBIUN), así como la Base de datos de libros editados en España de la Agencia Española del ISBN. Tratándose de una práctica eminentemente local, se prestó una especial atención a los catálogos de centros con importantes fondos de documentación local como la Biblioteca Pública de León y la Biblioteca de la Universidad de León. La búsqueda en todos estos catálogos se realizó mediante las palabras clave "lucha leonesa" y "aluche", filtrando los resultados obtenidos a partir de la aplicación de los criterios de inclusión descritos en el subapartado anterior. Una vez elaborado un listado definitivo de monografías a incluir en el repertorio estas se consultaron directamente para confirmar su incorporación y proceder a su descripción. 


\subsection{Sistema de descripción}

Para la descripción de cada referencia se ha seguido el proceso propuesto por PérezGutiérrez (2012). Este autor se basó en diversas normas UNE para su concreción, específicamente, las normas UNE 50-104-1994 "Referencias bibliográficas: contenido, forma y estructura", UNE 50103-1990 "Preparación de resúmenes", y UNE 50-121-1991 "Métodos para el análisis de documentos, determinación de su contenido y selección de los términos de indización" (AENOR, 1990, 1991, 1994), sobre las cuales únicamente se realizaron pequeñas modificaciones para ajustarse a los fines de su repertorio. El esquema de descripción propuesto por Pérez-Gutiérrez (2012, p. 186) consta de los siguientes elementos, que no han sido modificados para el presente repertorio:

Responsabilidad principal (Año). Título (Título: Subtítulo). Publicación (Lugar: Editor). Edición. Extensión: Ilustraciones; Tamaño (Alto x Ancho). Número normalizado. Publicaciones posteriores (Edición, Año de publicación). Palabras clave. Resumen.

Asimismo, se ha considerado interesante añadir algunos comentarios a algunas de las obras que componen el repertorio. Puesto que dichos comentarios no se ajustan propiamente a un resumen de dichas obras, estos se han añadido en notas al pie de página.

\subsection{Organización del repertorio}

El repertorio se ha organizado en una única sección, dado el escaso número de monografías que lo componen. Por este motivo, así como por la intención del autor de dotar de una cierta perspectiva histórica al trabajo, las referencias se han ordenado según un criterio cronológico de más antiguas a más modernas.

\section{Resultados: repertorio bibliográfico anotado de monografías de lucha leonesa}

1. García Blanco, Francisco Javier (1977). La Lucha Leonesa (de tradición folklórica a deporte federado). León: Institución "Fray Bernardino de Sahagun", Diputación Provincial de León C.S.I.C. $1^{a}$ ed. 141 p. : il. ; 16x21 cm. ISBN: 84-00-03679-4. Depósito legal: LE-1691-1977. Palabras clave: tradición, folklore, luchas típicas, evolución, anécdotas, reglamentación, deportivización, fuentes documentales. Resumen: Tesina de fin de carrera que fue premiada y publicada por la institución "Fray Bernardino de Sahagún". Consta de siete capítulos donde va abordando generalidades de la lucha, la lucha en España, el aluche leonés, la tradición y folklore con anecdotario y mapas, descripción y evolución, las mañas y finalmente las conclusiones. Contiene 55 láminas y figuras en $\mathrm{b} / \mathrm{h}$ fuera de texto. ${ }^{1}$

2. Rodríguez Cascos, Olegario y Gallego Provecho, Camino (1985). ¿Hay quién luche?. León: Patronato de Turismo y Deporte, Diputación Provincial de León. 1ae ed. 338 p. : il. ; 16x21 cm. ISBN: 84-505-2130-0. Depósito legal: LE-1015-1985. Palabras clave: lucha leonesa, recuerdos, leyendas, datos, historias, aluches, corros. Resumen: Compendio de información muy variada del ámbito de los corros de aluches. Sin aparente ordenación lógica escribe sobre corros históricos, luchadores famosos, anécdotas, hechos más o menos documentados, leyendas, etc. Consta de catorce capítulos donde va abordando la lucha antigua, la lucha leonesa de antes y actual, la primera comisión provincial de aluches, los campeonatos provinciales, aventuras y anécdotas, luchadores legendarios, reglamentos y merece especial atención el completísimo índice de luchadores con el que finaliza el libro.²

\footnotetext{
1 Fue el libro pionero de la lucha leonesa, a pesar de haber sido premiado y editado no tuvo mucha trascendencia social. El autor casi "se sintió obligado" por su director de tesina, el gran investigador y profesor suyo D. Miguel Piernavieja del Pozo, a abordar esta temática para su trabajo de fin de carrera.

${ }^{2}$ Uno de los autores, Olegario Rodríguez, fue delegado provincial de deportes del movimiento falangista en León, presidente de la federación de lucha leonesa, organizador, árbitro, escritor de la prensa, animador de corros de aluches. Todo ello le permitió estar en contacto directo con muchos antiguos luchadores y conocer de primera mano sus hazañas y vivencias. A su favor hay que reconocer el gran impulso que dio a la lucha leonesa y los bolos, y en su
} 
3. Rodríguez Cascos, Olegario y Gallego Provecho, Camino (1985). Los aluches. León: Patronato de Turismo y Deportes, Diputación Provincial de León. 1a ed. 24 p. : il. ; 21x16 cm. ISBN: No ISBN. Depósito legal: LE-1011-1985. [Colección Raíces no 4]. Palabras clave: aluches, mañas, luchadores, recuerdos, corros, relatos, cinto de honor, rivalidad. Resumen: Resumen muy esquematizado del libro de los mismos autores ¿Hay quién luche?

4. Rodríguez Cascos, Olegario (1985). Lucha leonesa, manual de aprendizaje. León: Patronato de Turismo y Deportes, Diputación Provincial de León. 1aㅡ ed. 21 p. : il. ; 20x15 cm. ISBN: No ISBN. Depósito legal: No depósito legal. Palabras clave: aluches, mañas, monitores, cultura física, corros, reglamento, enseñanza, costumbrismo. Resumen: Breve manual de enseñanza de los distintos aspectos a tener en cuenta para enseñar lucha leonesa. ${ }^{3}$

5. López Rodríguez, Cesáreo y De Celis, Ma Antonia (1999). La lucha leonesa de hoy: Manual didáctico. León: Diputación provincial. 1aㅡ ed. 149 p. : il ; 17x24 cm. ISBN: No ISBN. Depósito legal: LE-1.173-1995 (2 $2^{\text {a }}$ ed., 2003). Palabras clave: organización, reglamento, técnica, entrenamiento, alimentación. Resumen: Manual de lucha leonesa orientado a dar a conocer y difundir la lucha leonesa como deporte. Consta de cinco capítulos sobre equipamiento, instalaciones y organización de la lucha leonesa, fundamentos técnicos, entrenamiento, alimentación y reglamento y régimen disciplinario, más dos anexos con el régimen disciplinario y el vocabulario propio de este deporte. Profusamente ilustrado, particularmente en el capítulo de fundamentos técnicos.

6. López Rodríguez, Cesáreo (Coord.) (1999). Iniciación a la lucha leonesa: Manual completo del monitor. León: Diputación provincial de León y Federación Territorial de Lucha. $1^{\mathfrak{a}}$ ed. 206 p. : il ; 17x24 cm. ISBN: 84-605-8748-7. Depósito legal: LE-463-1999. Palabras clave: formación de entrenadores, historia, anatomía, fisiología, medicina del deporte, pedagogía, psicología, iniciación deportiva, reglamento, técnica, entrenamiento. Resumen: Manual de lucha leonesa orientado a la formación de monitores de la especialidad. Consta de diez capítulos en los que participan un total de nueve autores. Los capítulos, con una orientación genérica de iniciación deportiva y/o específica de lucha leonesa, se centran en las escuelas de lucha leonesa, historia de la lucha, iniciación deportiva, higiene, prevención de lesiones y primeros auxilios, educación física de base, técnica, psicopedagogía, cualidades físicas y reglamento.

7. López Rodríguez, Cesáreo (Dir.) (2000). El entrenamiento en los deportes de lucha. León: Diputación provincial de León y Federación Territorial de Lucha. 1a ed. 311 p. : il ; 17x24 cm. ISBN: No ISBN. Depósito legal: LE-1.164-2000. Palabras clave: formación de entrenadores, técnica, táctica, estrategia, entrenamiento, biomecánica, didáctica, valoración funcional, alimentación, medicina deportiva, análisis videográfico. Resumen: Manual de lucha leonesa orientado a la formación de entrenadores de la especialidad, específicamente en los ámbitos de planificación y control del entrenamiento. Consta de doce capítulos en los que participan un total de dieciséis autores. Los capítulos, con una orientación genérica de entrenamiento deportivo y/o específico de lucha leonesa, tratan aspectos físicos, técnicos, tácticos, estratégicos, psicológicos y didácticos ligados al entrenamiento en lucha leonesa.

8. Robles Tascón, Jose Antonio (2002). El deporte de los aluches en la literatura leonesa. Antología y estudio recopilatorio de textos desconocidos. León: Universidad de León. 1a ed. 191 p. : il ; 15x21 cm. ISBN: 84-7719-804-7. Depósito legal: LE-1000-2002. Palabras clave: historia, literatura, aluches. Resumen: Estudio orientado a dar a conocer textos literarios históricos relacionados con la lucha leonesa. Recoge más de una treintena de textos de diversa naturaleza (libros, diccionarios, cancioneros, publicaciones periódicas, etc.) publicados entre los siglos XVI y XX. Cada entrada se acompaña de una presentación en la que se contextualiza el texto

demérito ser muy poco riguroso con la comprobación de los datos que le iban dando los informantes. A pesar de todo el libro es una joya de la historia de la lucha leonesa.

${ }^{3}$ Surgió por la innovación de llevar la lucha leonesa a los colegios como modo de captación y desarrollo del número de niños y jóvenes practicantes. Hasta esa época los luchadores salían exclusivamente de la simple práctica tradicional en los pueblos. Este nuevo modelo conllevó la necesidad de formar a monitores o entrenadores que era una figura que no existía hasta entonces. 
trascrito. Profusamente ilustrado con dibujos y fotografías históricas sobre las luchas tradicionales en general y la lucha leonesa en particular.

9. Robles Tascón, Jose Antonio y Fernández Fernández, Fulgencio (2002). Historia de la Lucha Leonesa. León: El Mundo-La Crónica de León. 1a ed. 225 p. : il. ; 30,5x21,5 cm. ISBN: 84-6075201-1. Depósito legal: LE- 1177-2002. Palabras clave: historia, anecdotario, mitos, leyendas, resultados, aluches, lucha leonesa. Resumen: Monografía que tiene como finalidad hacer, por primera vez, un repaso histórico-cronológico de las distintas épocas que se han vivido en la lucha leonesa. Profusamente ilustrado con fotografías, documentos originales, prensa antigua, imágenes de antiguos trofeos, tablas, reglamentos, glosarios, etc. ${ }^{4}$

10. Robles Tascón, Jose Antonio y Álvarez del Palacio, Eduardo (2002). Didáctica de la lucha leonesa en la escuela: El acondicionamiento físico a través del juego. León: Caja España. 1a ed. 95 p. : il ; 12x23 cm. ISBN: 84-688-0507-06. Depósito legal: LE-1.495-2002. Palabras clave: iniciación deportiva, juego, acondicionamiento físico, educación, educación física, didáctica. Resumen: Manual orientado a promocionar y divulgar la lucha leonesa, especialmente entre el profesorado de educación física escolar. Consta de once capítulos en los que justifica la inclusión de la lucha leonesa en el sistema educativo ${ }^{5}$ y se abordan diversos elementos para facilitar dicha inclusión: elementos estructurales y funcionales de la lucha leonesa, objetivos, contenidos, secuenciación, pautas metodológicas, recursos y actividades, principalmente en forma de juego. Profusamente ilustrado con fotografías, dibujos y diagramas.

11. Robles Tascón, Jose Antonio (2003). La lucha, los aluches y los juegos populares y aristocráticos en la literatura española. León: Universidad de León. 1a ed. 206 p. : il ; 22x27 cm. ISBN: 849773-011-9. Depósito legal: S-4504-2003. Palabras clave: historia, literatura, juegos tradicionales, lucha, aluches. Resumen: Trabajo orientado a dar a conocer textos históricos sobre la lucha leonesa y contextualizarla como actividad lúdica tradicional. Consta de tres capítulos. El primero, elaborado por el Dr. Eduardo Álvarez del Palacio, estudia los juegos populares y aristocráticos en la España del s. XVI. El segundo realiza un recorrido histórico sobre los juegos desde la antigüedad a la época contemporánea, con especial atención a las luchas. Por último, el tercer capítulo, cuantitativamente el más extenso de la obra, recoge más de una treintena de textos específicamente relacionados con la lucha leonesa, extraídos de diversos tipos de fuentes, con su correspondiente contextualización. Profusamente ilustrado con dibujos y fotografías históricas sobre juegos, luchas y lucha leonesa.

12. Fernández Fernández, Fulgencio (2004). Historia de los Campeonatos Provinciales de Lucha Leonesa. León: Diputación de León. 1a ed. 132 p. : il. ; 24x16 cm. ISBN: No ISBN. Depósito legal: LE-1610-2004. Palabras clave: resultados, historia, anecdotario, mitos, leyendas, aluches, luches, lucha leonesa. Resumen: Estudio que tiene como finalidad hacer un recorrido histórico de la celebración de los distintos campeonatos provinciales de lucha desde sus comienzos en 1931 hasta la actualidad. Acompañado de multitud de anécdotas, leyendas sobre hazañas y proezas de luchadores, aventuras alrededor de la celebración de los concursos provinciales y variados relatos sobre el modo y medio de vida de aquellos hombres en cada una de las épocas.

13. González, Amancio y Rubio, David (2005). El aplauso de los chopos. León: LiberArte. 1a ed. 106 p. : il. ; 30x20 cm. ISBN: 84-609-4960-5. Depósito legal: LE-779-2005. Palabras clave: poesía, literatura, mitología, leyendas, narrativa, ensayo, aluches, luches, lucha leonesa. Resumen: Publicación que aglutina el acercamiento vivencial en primera persona y la narrativa de David Rubio, actual director del periódico La Nueva Crónica de León. A lo largo de la publicación el autor repasa sus inicios en el ambiente de la lucha leonesa desde cuando era niño en el pueblo y pasando por su época de becario-redactor de corros. El libro expone leyendas, conversaciones con luchadores históricos y las vivencias que a lo largo de esos años tuvo dentro del ambiente festivo en el que se engloba la celebración de los corros de aluches. Está ricamente ilustrado con láminas del famoso escultor leonés Amancio González.

\footnotetext{
${ }^{4}$ El libro fue editado en forma de 19 fascículos por el periódico y se agotaron los once mil ejemplares de la tirada corregida y aumentada. En la portada del libro destaca la foto más antigua de aluche leonés conocida hasta la actualidad que data de 1890. Fue prologado por el famoso escritor Julio Llamazares.

${ }^{5}$ Capítulo elaborado por el licenciado en educación física Álvaro Niño
} 
14. Robles Tascón, Jose Antonio (2005). Lo que usted debe saber sobre: Origen, evolución y pervivencia de los juegos y deportes de Lucha en Castilla y León. León: Caja España, Obra social.1a ed. 95 p. : il. ; 17x12cm, ISBN: 84-95917-26-2. Depósito legal: LE-1.857-05. [Cartilla de divulgación № 20]. Palabras clave: juego, lucha tradicional, edad media, arte románico, relieve, canecillo, capitel. Resumen: Estudio orientado a exponer una primera y escueta aproximación a las distintas representaciones artísticas de juegos de lucha en el arte medieval a lo largo de las nueve provincias de la Comunidad Autónoma. Con ello se pretende mostrar la extensión que tuvieron las actividades luctatorias a lo largo de todo el territorio y su relación con las modalidades tradicionales de lucha que existían hasta comienzos del siglo XX.

15. Robles Tascón, Jose Antonio (2007). Análisis y enseñanza de los gestos técnicos de la Lucha Leonesa: Las mañas de los Aluches. León: Celarayn.1a ed. 145 p. : il. ; 29x20 cm. ISBN: 978-84934676-5-4. Depósito legal: LE-1.522-2007. Palabras clave: entrenamiento, gestos técnicos, método de enseñanza, clasificación. Resumen: Trabajo orientado para dar a conocer el amplio repertorio de gestos técnicos o mañas de la lucha leonesa y contextualizarla como un deporte de combate más de nuestros días. Consta de siete capítulos. El primero, una introducción donde se plantea la necesidad de analizar desde una perspectiva moderna las mañas. El segundo explica el porqué del nombre de cada maña. El tercero una revisión de las clasificaciones de las mañas. El cuarto y quinto describen todos los gestos técnicos posibles y los que se pueden ejecutar. El sexto plantea una novedosa clasificación para su enseñanza basada en la seguridad, los requerimientos físicos necesarios para su ejecución y la complejidad técnica de cada maña. A continuación, se analizan, de los cincuenta posibles, veinticinco gestos técnicos describiendo y diseccionando ocho aspectos en cada uno: idea, clave, descripción, oportunidad, defensa, errores, fases y variantes. Está copiosamente ilustrado con más de mil imágenes. ${ }^{6}$

16. Fernández Fernández, Fulgencio (2008). Los Aluches. León: Diario de León. 1ae ed. 115 p.: il. ; 21x13 cm. ISBN 84-8012-650-2. Depósito legal: LE 752-2008. [Biblioteca leonesa de tradiciones, no 17]. Palabras clave: historia, orígenes, anécdotas, vivencias, mitos, leyendas, aluches, luches, lucha leonesa. Resumen: Estudio orientado a dar a conocer los aspectos más relevantes de tipo histórico, anecdótico, resultados, corros y campeonatos más destacados, mitos y leyendas de luchadores y otros personajes del mundo de los aluches. Todo ello se muestra de una forma amena y sencilla.

17. Fernández Fernández, Fulgencio (2013). Pioneras y luchadoras, la mujer en la lucha leonesa. Mansilla de las Mulas, León: Ayuntamiento de Mansilla de las Mulas. 1aㅡ ed. 44 p.: il. ; 20x14 cm. ISBN: No ISBN. Depósito legal: LE-945-2013. Palabras clave: mujer, historia, orígenes, anécdotas, vivencias, mitos, leyendas, aluches, lucha leonesa. Resumen: recorrido por el papel de la mujer en la lucha leonesa en su época moderna, desde inicios del siglo XX hasta nuestros días. Viaje a través del tiempo que parte de las reseñas literarias y de prensa en las que se pone de manifiesto que su único papel era el de espectadora como madre, hermana, novia o vecina, pero que tenía su importancia pues lo que el luchador defendía era el orgullo del pueblo y la presencia de las mozas alrededor del corro de aluches era un evidente aliciente. ${ }^{7}$

18. VV.AA. (2014). Al Corro: Cuentos de Aluches. León: Eolas Ediciones, León. 1a ed. 120 p. : il.; 21x15 cm. ISBN: 84-15603-52-8. Depósito legal: LE 595-2014. Palabras clave: poesía, literatura, anecdotario, mitos, leyendas, narrativa, ensayo, aluches, luches, lucha leonesa. Resumen: Publicación que aglutina la narrativa de 16 autores leoneses de reconocido prestigio como Julio Llamazares, Emilio Gancedo, Antonio Barreñada, Fulgencio Fernández, Francisco Flecha, Epigmenio Rodríguez, Pablo Andrés Escapa, Luis Artigue, Ángel Fierro, José Antonio Llamas, José Luis Puerto, Antonio Toribios, Miguel Paz Cabanas, Pedro García

\footnotetext{
${ }^{6}$ A partir de un conjunto inicial de diecinueve mil, tomadas de los corros de competición de lucha leonesa. Ello le da el valor de comprobar cómo se pone en práctica cada gesto técnico en situaciones reales de competición.

${ }^{7}$ En esos tiempos hubo algunas que se decidieron a agarrarse al cinto con sus vecinos. Así recordamos a pioneras como la hermana del excelente luchador Luis Rodríguez Verduras, que quiso saltar al corro cuando derrotaron a su hermano; como Cuquis la de Rucayo, que se agarraba con frecuencia a los chicos de este pueblo de gran tradición luchística o Cris de la Fuente, aún viva, poseedora de una cadrilada excelente que muchos luchadores recuerdan.
} 
Trapiello, David Rubio y José María Hernández. Cada uno de ellos diserta sobre las vivencias que ha tenido con el deporte de los aluches. Ilustrado por el escultor leonés Amancio González.

19. Martínez Murciego, Noemí y Barreñada García, Antonio (2015). Cuaderno de Aluches: descubriendo la lucha leonesa. León: Eolas Ediciones. 1a ed. 82 p. : il. ; 17x24 cm. ISBN: 8415603-90-0. Depósito legal: LE: 343-2015. Palabras clave: iniciación deportiva, juego, niños, jóvenes, educación, enseñanza, luchar, motivación, identidad leonesa. Resumen: El libro consta de cuatro capítulos. El primero trata de ejemplificar la progresión de los conceptos como jugar, combatir, competir, luchar. El segundo sobre la motivación para iniciarse en la lucha leonesa a través del reto y tú ¿quieres luchar? El tercero sobre el dominio que la habilidad o maña ha de tener sobre la fuerza en la lucha. El cuarto es una apuesta a las generaciones venideras por seguir manteniendo viva la práctica de la lucha leonesa. Está dirigido a los niños que dan sus primeros pasos en el mundo de la lucha leonesa, a los padres y madres, abuelos, a los veteranos y nuevos aficionados, porque todos ellos podrán acercarse a la lucha leonesa a través de estas sencillas y amenas explicaciones. Se pretende que este libro sea un medio visual, fácil y rápido para conocer las mañas de los aluches. ${ }^{8}$

\section{Consideraciones finales}

El presente repertorio recoge un total de diecinueve monografías de lucha leonesa, publicadas entre los años 1977 y 2015. Se trata de un número reducido en comparación con la literatura existente sobre otros deportes de combate (compárese por ejemplo con las referencias recogidas sobre diversas artes marciales en el repertorio de Pérez-Gutiérrez, et al., 2013), y considerando además la propia historia de la lucha leonesa. Resulta destacable, sin embargo, cómo la producción de monografías sobre lucha leonesa parece seguir una línea ascendente: si hasta el año 2000 únicamente se habían publicado cuatro monografías, las doce restantes se han publicado en las dos primeras décadas del presente siglo, lo cual parece indicar una mayor atención por este deporte tradicional en la literatura.

Por otra parte, la mayoría de obras publicadas sobre lucha leonesa tienen un carácter eminentemente local, atendiendo a los autores y editoriales que han publicado las monografías. Se aprecia también que ha existido un importante apoyo institucional (Diputación de León, Universidad de León, Federación Territorial de Lucha, Caja España) en la edición de obras, sumando más de la mitad de los trabajos publicados. En los próximos años, y gracias al reconocimiento logrado por la lucha leonesa como B.I.C. (Bien de Interés Cultural de Carácter Inmaterial), cabe esperar que este apoyo institucional siga manteniéndose, a la vez que pueda llegar a aumentar el interés de las editoriales privadas por la lucha leonesa.

Para terminar, las temáticas que abordan las monografías que componen el repertorio muestran claramente la doble dimensión de la lucha leonesa como deporte, ya sea en el ámbito del deporte educativo o del deporte rendimiento (e.g., López Rodríguez, 1999, 2000; López Rodríguez \& Flórez de Celis, 1995; Robles Tascón, 2007; Robles Tascón \& Álvarez del Palacio, 2002), y como tradición sólidamente enraizada y valorada en la historia leonesa (e.g., Fernández Fernández, 2004; Robles Tascón, 2003; Robles Tascón \& Fernández Fernández, 2002; Rodríguez Cascos \& Gallego Provecho, 1985). Posiblemente en el mantenimiento de este equilibrio deba encontrarse el futuro de los aluches.

\section{Referencias}

ACUERDO 33/2017, de 29 de junio, de la Junta de Castilla y León, por el que se declara la Lucha Leonesa, Bien de Interés Cultural de carácter inmaterial. (BOCYL no 125, de 3 de julio de 2017 y BOE no 165, de 12 de julio de 2017).

AENOR. (1990). Documentación: preparación de resúmenes. UNE 50-103-1990. Madrid: AENOR.

\footnotetext{
${ }^{8}$ Como señalan los autores en la presentación de la obra, "El futuro de nuestra identidad se encuentra arraigado en las costumbres y las tradiciones de nuestro pueblo. Es nuestra obligación como leoneses conservarlas y difundirlas para asegurar el legado de nuestros hijos”.
} 
AENOR. (1991). Documentación: métodos para el análisis de documentos, determinación de su contenido y selección de los términos de indización. UNE 50-121-1991. Madrid: AENOR.

AENOR. (1994). Referencias bibliográficas: contenido, forma y estructura. UNE 50-104-1994. Madrid: AENOR.

d'Orvenipe, D. L. (1898). Antiguos tratados de esgrima : (Siglo XVII). Madrid: [s.n.].

d'Orvenipe, D. L. (1901). Armas y desafíos : bibliografía de la esgrima y el duelo. Cuaderno primero. Madrid: [s.n.].

Fernández Fernández, F. (2004). Historia de los Campeonatos Provinciales de Lucha Leonesa. León: Diputación de León.

Fernández, F. (2002). Prólogo. In J. A. Robles Tascón (Ed.), El deporte de los aluches en la literatura leonesa. Antología y estudio recopilatorio de textos desconocidos (pp. 9-10). León: Universidad de León.

García Blanco, F. J. (1977). La Lucha Leonesa (de tradición folklórica a deporte federado). León: Institución "Fray Bernardino de Sahagun", Diputación Provincial de León - C.S.I.C.

Leguina, E. d. (1891). Libros de esgrima españoles y portugueses. Madrid: Impr. y Lit. de los Huérfanos.

López Rodríguez, C. (Ed.). (1999). Iniciación a la lucha leonesa: Manual completo del monitor. León: Diputación provincial de León y Federación Territorial de Lucha.

López Rodríguez, C. (Ed.). (2000). El entrenamiento en los deportes de lucha. León: Diputación provincial de León y Federación Territorial de Lucha.

López Rodríguez, C., \& Flórez de Celis, M. A. (1995). La lucha leonesa de hoy: Manual didáctico. León: Diputación de León.

Pérez-Gutiérrez, M. (2012). Repertorio bibliográfico, análisis bibliométrico y sociocultural de las monografías sobre artes marciales asiáticas publicadas en España [CD-Rom]. León: Universidad de León.

Pérez-Gutiérrez, M., \& Gutiérrez-García, C. (2008). 100 años de artes marciales: repertorio bibliográfico de monografías publicadas en España (1906-2006). León: Universidad de León.

Pérez-Gutiérrez, M., Brown, D. H. K., Álvarez, E., \& Gutiérrez-García, C. (2014). Asian martial arts bibliographies (1943-2013): A review. Ido Movement for Culture, 14(3), 1-9. doi: 10.14589/ido.14.3.1

Pérez-Gutiérrez, M., Gutiérrez-García, C., \& Álvarez del Palacio, E. (2013). Repertorio bibliográfico anotado de monografías de artes marciales asiáticas publicadas en España. Revista de artes marciales asiáticas, 8(1), 21-450. doi: 10.18002/rama.v8i1.836

Robles Tascón, J. A. (2002). El deporte de los aluches en la literatura leonesa. Antología y estudio recopilatorio de textos desconocidos. León: Universidad de León.

Robles Tascón, J. A. (2003). La lucha, los aluches y los juegos populares y aristocráticos en la literatura española. León: Universidad de León.

Robles Tascón, J. A. (2007). Análisis y enseñanza de los gestos técnicos de la Lucha Leonesa: Las mañas de los Aluches. León: Celarayn.

Robles Tascón, J. A., \& Álvarez del Palacio, E. (2001). La lucha leonesa de antaño: Los aluches. Apunts: Educación física y deportes(66), 72-76.

Robles Tascón, J. A., \& Álvarez del Palacio, E. (2002). Didáctica de la lucha leonesa en la escuela: El acondicionamiento físico a través del juego. León: Caja España.

Robles Tascón, J. A., \& Fernández Fernández, F. (2002). Historia de la lucha leonesa. León: El MundoLa Crónica de León.

Rodríguez Cascos, O., \& Gallego Provecho, C. (1985). ¿Hay quién luche? León: Diputación provincial.

\section{Author's biographical data}

José A. Robles-Tascón (España), es Profesor Titular de Universidad del Departamento de Educación Física y Deportiva de la Universidad de León. Entrenador nacional de lucha grecorromana y libre olímpica y preparador físico y entrenador de deportistas de lucha leonesa, fue un destacado competidor de esta modalidad. Sus líneas de investigación comprenden las luchas tradicionales en la península ibérica, el juego y la actividad física en la Edad Media y el Renacimiento, los juegos y deportes populares en la educación física actual y el acondicionamiento físico y la salud en niños y jóvenes. E-mail: jarobt@unileon.es 
Héctor García-Robles (España) es Licenciado en Educación Física y doctorando del antiguo programa Ciencias de la Actividad Física y el Deporte de la Universidad de León. Con 16 campeonatos provinciales obtenidos, posee el record absoluto en la historia de la lucha leonesa, además de otros muchos títulos en diversas modalidades de luchas tradicionales (back-hold, gouren, kurash, s'istrumpa, etc.). Actualmente trabaja como Técnico Coordinador de Deportes Ayuntamiento Villaquilambre (León). E-mail: Hectorgarcia@villaquilambre.es 